\title{
Training In Diversity Management
}

Sonja Treven, (E-mail: sonja.treven@uni-mb.si), University of Maribor, Slovenia

Urska Treven, (E-mail: urska.treven@uni-mb.si), University of Maribor, Slovenia

\begin{abstract}
The labor force all around the world is becoming increasingly diverse. Thus, organizations that can manage employee diversity effectively gain a competitive advantage. In such organizations diversity training is a necessity. Diversity training helps managers understand and value individual differences and develop strong diagnostic skills. The paper explores various approaches to training, like awareness-based and skill-based diversity training. A special attention to potential problems that may occur in the process of diversity training is given.
\end{abstract}

\section{INTRODUCTION}

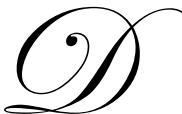

iversity should be a mayor concern in any organization and valuing diversity in all aspects of operations should be a top priority. With diversity comes differences, and with differences comes the potential for problems and relationships. But, importantly, too with diversity comes the great potential for new perspective, creativity, and expanded problem solving that can be important in meeting the demands of our complex and dynamic work environments. The organizations that best understand and best deal with employee diversity (ED) and individual differences are poised to achieve competitive advantage.

In the paper we shall define the term employee diversity in the first place. Then we shall turn our attention to ED elements, like various types of personality, values and attitudes of employees, their family issue, and demographic trends that managers should know in order to manage their ED in the organization successfully. We shall also present the characteristics of successful ED management. As one of the key strategies for ED management success is training, we shall examine various types of diversity training, like awareness-based and skill-based diversity training. We shall conclude the paper with the quotation of potential problems that may occur in the process of diversity training as well as consider several notes of caution for successful diversity training.

\section{DIVERSITY OF EMPLOYEES}

Diversity represents the multitude of individual differences and similarities that exist between people. In literature there are many various definitions of ED. We shall apply the simplest definition: ED refers to human characteristics making employees mutually different. Sources of individual variations are complex, but they can be grouped into two categories: 1) those over which we have little or no control, and 2) those over which we have more control (Greenberg, Baron, 2000). The first group includes biologically determined characteristics such as race, sex, age, and certain physical attributes, as well as the family and society, history, in which we live. These factors exert a powerful influence on individual identity and directly affect the manner of person's relation to other individuals and groups both in general and at work. In the second category there are characteristics that people can adopt, drop, or modify through conscious choice and deliberate efforts. These include marital status, political beliefs, geographic location, work background, and education/profession.

Employees who belong to the same age, gender, professional etc. group often have similar patterns of behavior. As organizations become more diverse because of e.g. globalization, differences among groups can become more pronounced and lead to problems in EDM. In this article, we shall try to provide some solutions for training in EDM. In order to do this, we must explain the meaning of the term EDM, first.

Most definitions of EDM include three main points (Schermerhorn et al., 2004; Kandola, 1995): 1) effective management of diversity and differences among employees can add value to a company; 2) ED includes all types of 
differences, not only the obvious physical differences such as gender or ethnicity, and 3) organizational culture and working environment issues are concerns of EDM.

The contemporary view of EDM compares ED with a mosaic. Differences come together to create the whole organization, in much the same way as the single pieces of mosaic come together to create its synergetic image. Differences in organizations are acknowledged, accepted, and have a place in its integral structure (Schermerhorn, et al, 2004).

\section{TYPES OF EMPLOYEES PERSONALITY}

Diverse personnel structure in organizations includes individuals with different types of personality and their synergies. In order to present some significant types of personality, we must first explain what the term "personality" means. According to Gordon (1999) personality relates to a great number of unique personal traits, motives, feelings, values, interests, and abilities. These characteristics are influenced mostly by heredity and cultural as well as family environment in which the person lives.

Psychologists examined various aspects of personality and explained their impact on the behavior in work settings. In this chapter we shall present the dimensions of personality that are important for organizational behavior. They appear in several synergies of dimensions. The overall quality of synergy depends on job and situation to be mastered.

\section{Extroversion - Introversion}

Swiss psychiatrist Carl Gustav Jung classified people on the basis of direction to which their physical energy. People who turn it to the external world and to other people are called extroverts, while he marks the others as introverts (Jung, 1994; Jung and others, 2003). Extroversion as a basic personality dimension includes sociability, vivacity, spirit of enterprise, active and impulsive behavior, interest for surroundings, while introversion points out unsociability, careful, reserved and considerate behavior, interest for one's own experiencing as well as for the internal, subjective world (Musek, 1993).

\section{Adjustment To Organizational Life}

Any employee must (actively) adjust to its organization. The success of his/her adjustment to it usually depends on his/her personality. Regarding successfulness of person's adjustment to the organization, we distinguish three basic groups of personalities (Presthus, 1978): 1. the organizationalist: is a person with a strong commitment to his/her job and has strong identification with the organization; 2. the professional: is a person who is job centered, tends to view organization demands as pressure; and 3. the indifferent: is a person who works for pay, work is not a critical part of his/her life structure.

\section{Authoritarianism, Machiavellianism And Bureaucraticism}

Authoritarianism is a belief that there should be status and power differences among people in organizations (Staw, 2003; Vecchio, 2000). People with an authoritarian personality believe in obedience and respect for authority, and that the strong should lead the weak. Maslow says that true authoritarians will take advantage of others, and the best way to deal with them is to assert your own authority, if possible (Maslow, 1965). Machiavellian personality includes many similar traits as the authoritarian one. An individual exhibiting strong Machiavellian tendencies is pragmatic, maintains emotional distance, and believes that ends can justify means. Persons with bureaucratic personality value hierarchy, rule conformity, and impersonal and formal relationships.

\section{Locus Of Control}

Some people believe that they are masters of their own fate. Other people see themselves as pawns of fate, believing that what ever happens to them in their lives is due to luck or chance. Locus of control in the first case is internal, 
while it is external in the second case. Evidence shows that employees who rate high in externality are less satisfied with their jobs, more alienated from the work setting, and less involved in their jobs than internals (Robbins, 1998).

\section{Risk Propensity}

People differ in their willingness to take chances, too. Individuals with a high-risk propensity make more rapid decisions and use less information in making their choices than low-risk propensity individuals. Managers might use this information to align employee's risk-taking propensity with specific job demands (Rogers, 2003).

\section{Type A And B Personality}

People with type-A personality are action and results oriented, and hurry to complete work and move on to the next task. They tend to work faster and harder than persons with type-B personality. Type-B persons are calm and unruffled. They rarely demonstrated high levels of emotion even in a crisis or emergency (Pettinger, 2002).

\section{VALUES AND ATTITUDES OF EMPLOYEES}

Values and attitudes of a person develop over time, beginning in early childhood. They are often dependent on personality and can influence behavior. For managers and other employees it is important to understand the nature and the impact of values and attitudes in their work environment. That may help them to solve problems at the workplace more effectively.

Values of an individual refer to the basic principles and tenets that guide a person's beliefs, attitudes, and behaviors (Schermerhorn et al, 2004). They tend to be relatively stable characteristics, often developed in childhood. Values become evident in work and non-work settings throughout adulthood. People's values can influence their beliefs about money, the importance of work, social interactions, and other aspects of their work and non-work lives.

Attitudes reflect a person's likes and dislikes, their affinities and aversions toward any identifiable object in their environment (Tossi et al, 2000). They are predispositions for favorable or unfavorable reactions to almost everything in the world around us. They reflect what people find good or bad and are thus evaluative in nature. The concept of attitude is complex. It tackles also components and dynamics of attitudes.

The more the employee structure in an organization is diverse, the more likely people have various attitudes. They have an array of beliefs, which have predominantly formed by the interconnection with their socioeconomic and cultural background and other experiences. These differing beliefs often result in different attitudes. Recent researches have shown that attitudes toward various ethnic groups and different races as well as gender roles have changed considerably (Tossi, Mero, 2003). Such differences in attitudes of employees present a significant issue for managers who are responsible for effective ED management in their organizations.

\section{FAMILY ISSUES}

Responding to issues related to the interaction between work and family has become particularly important in managing a diverse workforce in Slovenia as well as in other market oriented economies. The family issues vary significantly, depending on age and marital, parental, and/or economic status (Hellriegel, Slocum, 2004).

At an age over 20, an individual usually gets employed for the first time, creates feelings about him/herself and increases his/her independence from parents. In this period, he/she decides where to live and how to dispose time and energy among work, parents, and friends. After marriage one copes with the challenge of living with the spouse. $\mathrm{He} / \mathrm{she}$ has to coordinate his/her own needs with the needs of his/her spouse. If the organization sends one of both to an assignment abroad for a longer period of time, special circumstances may appear.

Parents of young children often cope with a serious problem trying to find a proper balance between their work and responsibilities at home. They are emotionally tied to their children, have to provide for their guardian when 
they are absent, and have to determine the responsibilities of one or another, or even of both parents. Parents of teenagers may be burdened with their children's desire for independence, dissatisfaction with their behavior, as well as with the crises, which they face in this period of life. Because their parents are rather old, they often worry for their health and well-being (Treven, 2001).

When children leave home, their parents are about 50. They can concentrate on their interests connected with their work settings and home. Later, when they become grandparents, they may help their children look after their grandchildren. At this stage of life they may also care for their sickly spouse, or even establish a new family.

\section{DEMOGRAPHIC TRENDS}

In organizations around the world we can notice some demographic trends that have increased ED. Thus, number of racial and ethnic groups members, women and elder workers, as well as percentage of their family members, in which both parents are concerned with their own career, has increased in work settings (Schermerhorn et al, 2004).

When Slovenia was still part of Yugoslavia the percentage of members of different nations, mostly Bosnians, Kosovo's Albanians, Croats, and Serbs has increased significantly and today they represent about $10 \%$ of entire population. They moved to the most developed former republic in Yugoslavia in order to earn more and to live in better life conditions as they had had back home. The intention of thousands of refugees from Asian and African countries who have recently legally or illegally moved to the Western European countries, Canada, USA, Australia, and New Zealand is quite similar.

The number of women in organizations throughout Slovenia has been constantly increasing, too, during the last 50 years and has reached about one half of all employees already. We can notice a similar trend in developed countries of western and northern Europe according to which women, similarly to their male colleagues, strive for their own career development.

Recently we have read a lot about aging of population in Slovenia as well as in other developed, market oriented countries in daily newspapers as well as in technical magazines. Because of such demographic facts we can expect the median age of the labor force in those countries to increase in forthcoming decade. Employees will also tend to remain in the workforce well past the age at which their parents retired. Managers in organizations cannot discriminate on the basis of age and must adjust the tasks to the needs of older workers (Robbins, 2005).

\section{EMPLOYEE DIVERSITY MANAGEMENT (EDM)}

ED and individual differences belong to crucial issues challenging managers in the quest for high performance and organizational competitiveness by EDM. This is true not only in Slovenia as well as in other European Union countries but also in the United States and in other countries. Hence, let us try to answer the question: $»$ what do we mean by $\mathrm{EDM} \ll$ ?

EDM entails enabling people to perform up to their maximum potential, either in spite of their diversity or on its basis, resulting in their complementary attributes and interdependence. It focuses on changing an organization's culture and infrastructure for people to provide the highest productivity possible (Kreitner and others, 2002). Changing here means innovation that is change bringing new benefit to its users (not all changes are innovations, but all innovations are changes) (EU, 1995). Ann Morrison (1992), an ED expert, conducted a study of 16 organizations that successfully managed diversity. Her results uncovered three key strategies for EDM success: 1) Education; 2) Enforcement; and 3) Exposure.

- The education component of EDM strategy has two thrusts: one is to prepare the less-traditional managers for increasingly responsible posts; the other to help traditional managers overcome their prejudices by thinking about and interacting with people of a different sex, ethnicity, etc. 
- $\quad$ The enforcement component of EDM strategy puts teeth in diversity-related goals and encourages behavioral change / innovation.

- $\quad$ The final EDM component, exposure to people with different backgrounds and characteristics, adds a more personal approach to ED by helping managers get to know and respect others who are different.

The EDM concept in organizations emphasizes a) appreciation of differences, and b) creating a setting where everyone feels valued and accepted. An organization's success or progress in EDM can be monitored by organizational surveys of attitudes and perceptions, among other means. EDM assumes that groups will retain their own characteristics and will shape the company as well as be shaped by it, creating a common set of values that will c) strengthen ties with customers, enhance recruitment, and the like. Sometimes, EDM is resisted because of fear of change and discomfort with differences (Schermerhorn et al, 2004).

\section{DIVERSITY TRAINING}

Nowadays, many companies offer diversity training. Such training refers to a series of programs and activities that highlight differences among workers and offer strategies for handling them. Diversity training programs are intended to provide a vehicle for increasing awareness and examining stereotypes. Participants learn to value individual differences, increase their cross-cultural understanding and confront stereotypes (Robbins, 1998).

The typical diversity training program lasts from half a day to three days in length and includes role playing exercises, lectures, discussions, and group experiences. For example, a training exercise that sought to increase sensitivity to aging asked participants to respond to the following four questions: (1) If you didn't know how old you are, how old would you guess you are? In other words, how old do you feel inside? (2) When I was 18, I thought middle age began at age __. (3) Today, I think middle age begins at age ___. (4) What would be your first reaction if someone called you an old worker? Answers to these questions can then be used to analyze age-related stereotypes. In another program designed to raise awareness of the power of stereotypes, each participant is asked to write an anonymous paper detailing all groups - women, born-again Christians, Moslems, gays, gypsies, men - to which they had attached stereotypes. They were also asked to explain why they'd had trouble working with certain groups in the past.

\section{VARIETIES OF DIVERSITY MANAGEMENT PROGRAMS}

In general, diversity management programs are divided into two categories: 1 . awareness-based diversity training, and 2. skill-based diversity training. Both approaches have the same long-term goals, which are summarized in Figure 2. They strive to make interaction between diverse groups of people easier and more effective. Once people are paying attention to each other, the road is paved to morale to improve, productivity to be enhanced, and people to focus their creative energies.

Diversity training helps managers understand and value individual differences and develop strong diagnostic skills. Dissemination of factual information may change some beliefs, but more emotion-oriented persuasive techniques and long-term educational efforts may be needed to alter them (Greenberg, Baron, 2000; Gordon, 1999).

\section{Awareness-Based Diversity Training}

Specifically, awareness-based diversity training is designed to raise people's awareness of diversity issues in the workplace and to help them recognize the underlying assumptions they make about people. It is a very basic orientation - and one that takes a cognitive approach. Usually, it involves teaching people about the business necessity of valuing diversity, and it makes them sensitive to their own cultural assumptions and biases. This may involve various experiential exercises as well as real-life case studies that help people to view others as being individuals, not stereotyped members of groups. 
An example of such case studies: A patient, an elderly white man, comes into a health center for a blood test. When a gipsy clinician appears to give the test, the patient balks. Does the office manager bow to the patient's wishes or politely assert the company's right to say only the gipsy employee will draw the blood?

The training tries to help people learn to respond to such differences with sensitivity.

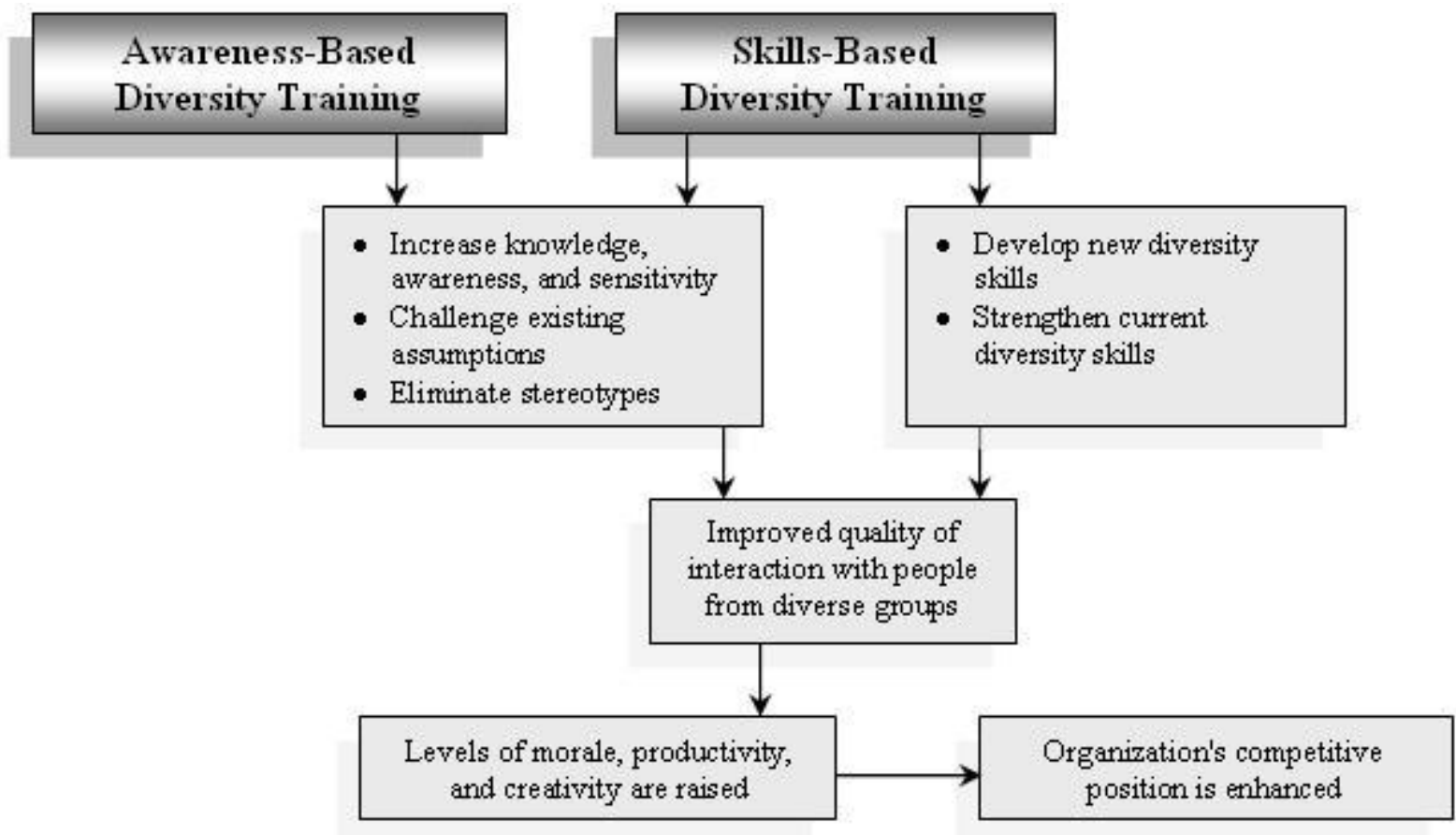

Figure 2. Two Major Approaches To Training (Greenberg, Baron, 2000)

\section{Skill-Based Diversity Training}

Building on the awareness approach is skill-based diversity training. This orientation is designed to develop people's skills in managing diversity. As such, it goes beyond raising awareness. It develops the tool needed to interact effectively with others. Four main tools are involved in this process. These include:

- Cross-cultural understanding. Understanding the cultural differences responsible for why different coworkers behave differently on the job (Treven, 2005a; Klarič, 2005).

- Intercultural communication. Learning to overcome verbal and nonverbal barriers to communication across cultures (Treven, 2004; Treven, 2005b).

- $\quad$ Facilitation skills. Training in helping others to alleviate misunderstandings that may result from cultural differences.

- $\quad$ Flexibility and adaptability. Cultivating the ability to patiently take new and different approaches when dealing with others who are different.

\section{POTENTIAL PROBLEMS IN DIVERSITY TRAINING}

Several important notes of caution need to be carefully considered when it comes to successful diversity training. Some of the potential problems in diversity training as well as their description and solution are as follows (Greenberg, Baron, 2000): 
- $\quad$ Emotional tension is heightened. Talking about prejudices is likely to make people uneasy. Training needs to be conducted in a "safe", comfortable environment.

- $\quad$ Possibility of polarization. Avoid discussions that have yes or no answers. Instead, encourage consideration of a broad range of options.

- $\quad$ Some people may have personal "axes to grind". Training sessions should not provide platforms for people who want to vent about past problems.

- $\quad$ Personal attacks may occur. Strong opinions on diversity issues may box people into corners. Treat everyone with respect and dignity.

- $\quad$ Reactions to training will be varied. Some may welcome the training, whereas others may resent having to go through it. Addressing these feelings should be made a part of training sessions.

- $\quad$ White males tend o to be blamed. It is tempting to blame the dominant group, white males, for diversity problems, but no one group has a monopoly on prejudice and discrimination. White males should discuss their difficulties adjusting to a changing world.

- $\quad$ Timing may be problematic. Avoid adding to stress by not scheduling sessions during periods in which other sensitive events (e.g. layoffs, contract negotiations) are occurring.

- $\quad$ Reasons for training may be ingenuine. Diversity training works best when part of a strategic effort by management to change policies to make a more "inclusive" organization. Training conducted because "everyone's doing it", however, is likely to fail - and maybe even backfire.

\section{MANAGERIAL RECOMMENDATIONS TO ADRESS THE POTENTIAL PROBLEMS}

Perhaps the main key to effective diversity management is complete managerial support. Successful diversity management requires sustained action to diversity in all organizational activities. For example, companies with successful diversity management training programs also tend to require everyone to be trained, to define diversity very broadly (i.e., they do not limit it to only one or two groups), and to reward managers for special efforts at increasing diversity. Without completely supporting diversity activities, organizations may find themselves quite disappointed with their efforts.

Although mistakes have been made in some diversity management programs, such programs in many cases have greatly helped organizations find ways of tapping the rich pool of talent in a highly diverse workforce.

In addition, the company diversity council (CDC) may be established. A CDC is a group of managers who are responsible for issues connected with diversity in the company. It needs also a vice presidential-level person to oversee its effort. This council can set up specific actions to serve as the initial focus of the diversity efforts. Its goals are: 1 . to create accountability for measuring diversity, 2. to provide a custom-made education program, 3 . to develop an explicit code of conduct and communication with a zero-tolerance policy (for example, the code spells out inappropriate behavior such as racist jokes and creates appropriate expectations and behavior standards), 4. to commit to creating diverse candidate pools for all managerial hiring and promotion decisions, and 5. to use cultural audits, surveys, focus groups, and broad networking groups to assess diversity.

Each year, the CDC may attempt to increase the employee diversity in terms of the proportion of women and racial minorities, which allows for continuous improvement. It can also initiate the carefully phrased opinion survey in which questions such as how employees feel they are valued; what they feel their career opportunities are; and how well the organization supports work-life balance, are asked. The CDC uses improvements in these areas as partial indicators of successful diversity. It may also include the Disability Council, a group similar to CDC in companies with high proportion of disabled employees, to help the company keep on abreast of issues relevant to this group of employees. This group also can help to attract additional customers.

\section{CONCLUSIONS}

To tap the rich pool of resources available in today's diverse workforce, companies may use diversity management programs - that is, techniques for systematically teaching employees to celebrate the differences between people. Typically, these programs go beyond efforts to recruit and hire women and minorities. They can create 
supportive work environments for them as well. The most effective programs not only focus on enhancing awareness of the benefits from a diverse workforce but on developing skills that help employees to embrace diversity.

Implementing diversity management programs is potentially difficult, but the benefits - both organizational and personal - are considerable. For example, companies with employees who systematically embrace diversity tend to be more profitable than those that allow discrimination to occur.

\section{REFERENCES}

1. $\quad$ EU (1995). Green Paper on Innovation. www.cordis.lu/cordis/grnpaper.html

2. Gordon, J. R. (1999). Organizational Behavior. Prentice Hall International: New Jersey.

3. Greenberg, J. and Baron, R. A. (2000). Organizational Behavior. Prentice-Hall: New Jersey.

4. Hellriegel, D. and Slocum, J. W. Jr. (2004). Organizational Behavior. Thomson South-Western: Mason, Ohio.

5. Jung, C. G. (1994). Sodobni človek išče dušo. Julija Pergar: Ljubljana.

6. Jung, C.G., von Franz, M.L., Henderson, J.L., Jacobi, J., and Jaffẻ, A. (2003). Človek in njegovi simboli. Mladinska knjiga Založba d. d.: Ljubljana.

7. Kandola, R. (1995). Managing Diversity: New Broom or Old Hat? International Review of Industrial and Organizational Psychology, 10: 131 - 67.

8. Klarič, Š. (2005). Skrb za izseljene managerje v procesu kulturne prilagoditve. M.A. Thesis, University of Maribor, Faculty of Economics and Business, Maribor.

9. Kreitner, R., Kinicki, A., and Buelens, M. (2002). Organizational Behaviour. McGraw Hill Publishing Company: Berkshire.

10. Maslow, A. H. (1965). Motivation and Personality. Harper \& Row: New York.

11. Morrison, A.M. (1992). The New Leaders: Guidelines on Leadership Diversity in America, San Francisco: Jossey-Bass.

12. Pettinger, R. (2002). Stress Management. Capstone Publishing (A Wiley Company): Oxford.

13. $\quad$ Presthus, R. (1978). The organizational society. St.Martin's Press: New York.

14. Robbins, S. P. (1998). Organizational behavior. Prentice-Hall International: New Jersey.

15. Robbins, S. P. (2005). Essentials of Organizational Behavior. Prentice-Hall International, New Jersey.

16. Rogers, E. M. (2003). Diffusion of Innovation. Fifth Edition. The Free Press: New York.

17. Schermerhorn, J.R. Jr., Hunt, J.G., and Osborn, R.N. (2004). Core Concepts of Organizational Behavior. Wiley: Hoboken, NJ.

18. Staw, B.M. (2003). Pschological Dimensions of Organizational Behavior. Pearson Education: New Jersey.

19. Tossi, H. L., Mero, N.P., and Rizzo, J. R. (2000). Managing Organizational Behaviour. Blackwell Publishing: Oxford.

20. Tossi, H. L. and Mero, N. P. (2003). The Fundamentals of Organizational Behavior. Blackwell Publishing: Oxford.

21. Treven, S. (2001). Organizacijsko vedenje. Gospodarski vestnik: Ljubljana.

22. Treven, S. (2004). Human resource management on a global basis. In: The Information Technology \& Global Business Research Conference, March 10-13, 2004, Cancun, Mexico. Research Forum: Technology \& Business Forum, Vol. 1, Num. 1.

23. Treven,S. (2005a). Human resources management in the global environment. The Journal of American Academy of Business, Mar. 2006, vol. 8, no. 1, pp. 120-125.

24. Treven, S. (2005b). The connection between culture and organizational behavior. International business \& economics research journal, 2005, vol. 4, no. 7, pp. 49-57.

25. Vecchio, R. P. (2000). Organizational Behavior. The Dryden Press: Forth Worth. 